\title{
JOB LOSSES, OUTSOURCING AND RELOCATION: EMPIRICAL EVIDENCE USING MICRODATA* $^{*}$
}

\author{
by Manuel Artís§, Raül Ramos†, and Jordi Suriñach $\ddagger$ \\ $\S$ Grup d'Anàlisi Quantitativa Regional (AQR), IREA, University of Barcelona, \\ Dept. of Econometrics, Statistics and Spanish Economy, Avda. Diagonal 690, \\ 08034 Barcelona, Spain; email: manuel.artis@ub.edu \\ † Grup d'Anàlisi Quantitativa Regional (AQR), IREA, University of Barcelona, \\ Dept. of Econometrics, Statistics and Spanish Economy, Avda. Diagonal 690, \\ 08034 Barcelona, Spain; email: rramos@ub.edu \\ ‡ Grup d’Anàlisi Quantitativa Regional (AQR), IREA, University of Barcelona, \\ Dept. of Econometrics, Statistics and Spanish Economy, Avda. Diagonal 690, \\ 08034 Barcelona, Spain; email: jsurinach@ub.edu
}

\begin{abstract}
Using microdata, we analyse the determinants of firm relocation and conventional outsourcing decisions as a way to reduce employment. The results for a sample of 32 countries show the relevance of factors not considered previously in the literature. Firms that are below average in quality or innovation have a higher propensity to externalise part of their production through outsourcing, while lower relative profitability and longer time to market for new products each imply a higher probability of relocation.
\end{abstract}

\section{Background and objectives}

Due to the fast emergence of new competitors both in the industrial sector (China) and in the services sector (India), together with the recent enlargement of the European Union to the east, fears of job losses have increased among European citizens during the last few years.

Several studies have analysed the potential risks of firm relocation and outsourcing on macroeconomic performance ${ }^{1}$, but only a few studies have

\footnotetext{
* Financial support is gratefully acknowledged from the Spanish DGI SEJ2005-04348/ECON project. We are also grateful to Carlos Obeso for providing us access to the CRANET database.
} 
adopted a microeconomic approach. The identification of which jobs will be lost in the future, looking at past evidence at the firm level, is clearly relevant from a policy perspective. If we can identify which firms are likely to externalise part of their production or even move to a different location, proper policy measures may be taken to provide support to the most affected sectors or territories.

In this paper, we analyse the two different phenomena and their potential negative effects on employment: on one hand, we look at the determinants of firm relocation (total or partial) and, on the other hand, we study the characteristics of firms using subcontracting as a way to externalise part of their production processes.

The potential adverse effects of firm relocation on employment have been highlighted by the literature, particularly for large, multi-plant firms. The geographical movement of these kinds of firms in search of the most favourable locations (i.e. with lower wages) implies the destruction of jobs in the home country (Sleuwaegen and Pennings, 2004).

Subcontracting or outsourcing ${ }^{2}$ refers to the procuring of part of a product or process from an outside firm through long-term arrangement. As Tayman and Kiliçaslan (2005) highlight, it is widely established that subcontracting can play an essential role in regional networking and development. However, subcontracting relationships between large firms and small subcontractor firms do not necessarily have a developmental nature because large firms tend to transfer the burden of risks and costs onto their subcontractors (usually implying net job losses in the medium-to-long term). Subcontracting can therefore have negative effects on employment when it is used to externalise production.

Our objective in this paper is to identify the determinants of firm relocation and subcontracting $^{3}$ at the firm level, to identify potential negative effects on employment, and to check whether any differences arise between relocation and subcontracting.

The main contributions of the paper draw on previous work as follows. Firstly, we make use of a dataset for the period 2003-2005, a period in which

\footnotetext{
${ }^{1}$ See Amiti and Wei (2005) and Boulhol and Fontagné (2006) for two of the most recent and comprehensive studies in this context. The first analyses the services sector while the second focuses on manufacturing.

${ }^{2}$ As Kimura (2002) highlights, several studies have used the word "outsourcing" to refer to the same phenomenon.

${ }^{3}$ It is worth mentioning that both situations could be related to offshoring, but not necessarily. Offshoring refers to taking advantage of lower-cost labor in another country. A common misconception is that all offshoring involves outsourcing, but this is not true. While outsourced processes are handed off to an external firm, offshored processes can be handed off to external firms or remain in-house. In the second case, a partial relocation of activity is implied. For this reason, both phenomena-firm relocation and outsourcing-can have negative effects on employment in the country of origin.
} 
globalisation was growing and, at the European level, the introduction of the euro was completed and the single market took major steps forward. As a result, we expect firm relocation to be more relevant in this period than previously. Secondly, we consider a wider sample of countries than in earlier studies, although focusing on the EU-15 countries. Lastly, following lines of research suggested by Brouwer et al. (2004), we consider the relative performance of firms within their own sectors, analysing various aspects (quality, productivity, profitability, time to market, and innovation) as potential determinants of relocation and outsourcing decisions.

The rest of the paper is organised into three sections: firstly, in the second section, the existing literature is briefly summarised; then, in the third section, the dataset and the empirical evidence obtained are described; and lastly, the paper concludes with some final remarks.

\section{Related literature}

This section focuses only on those previous studies considering outsourcing and relocation decisions from a microeconomic perspective.

From a theoretical perspective, as highlighted by Brouwer et al. (2004), relocation processes can be analysed in terms of neoclassical, behavioural and institutional theories.

The neoclassical theory takes as a starting point the assumption that the location choice tries to maximise firm profits. From this perspective, determinants of firm relocation usually involve the characteristics of the host country relative to those of the home country. These characteristics can be related to market size, wage levels, worker education levels and so on.

The behavioural location theory explores "internal" factors that are important in the decision-making process of a firm considering relocation. In particular, factors such as firm age and size are highlighted as relevant by this literature.

Lastly, the institutional theory predicts that firm location is an outcome of a firm's investment strategy and is, as a result, clearly influenced by external factors such as the growth in economic activity, the level of state intervention, or any involvement in a merger, takeover, or other similar situation.

Similarly, as regards outsourcing, Kimura (2002) summarises the theoretical foundation of subcontracting according to four different approaches. The first is the transaction cost approach. Subcontracting arrangements can be interpreted as one of the tools available to minimise transaction costs. The second is the game theory approach, which emphasises the long-term cooperative relationship between upstream and downstream firms based on a repeated game, reputation and coordination. The third is the economics of 
information approach. This approach is based on the contract theory, in particular the principal-agent model in which long-term relationships serve to foster efficient risk-sharing arrangements under incomplete information. Lastly, the network approach has been formulated specifically for the Japanese case. It advocates that the Japanese inter-firm relationship be interpreted as an "intermediate" organisation in which the market principle and the organisational principle coexist. It emphasises that, in a certain economic environment, interfirm relationships are built, based on efficient synergies between competition and coordination.

From these four approaches, theoretical predictions can be extracted about the characteristics of a firm likely to subcontract. In particular, the transaction cost approach and the network approach suggest that subcontracting will be preferred to vertical integration when production requires specialised technology or skilled labour or when a firm's environment is particularly suited to collaboration (industrial clusters). The game and the information approaches describe path dependence in subcontracting and the logic of saving monitoring costs. Thus, as with relocation decisions, subcontracting also seems to depend on location factors, internal factors and external factors. Table 1 summarises the findings of the above theoretical studies.

\section{TABLE 1}

From an empirical perspective, the first study to our knowledge that analyses relocation determinants at the firm level is Pennings and Sleuwaegen (2000). Using microdata on firms located in Belgium, they found that labour-intensive firms with a large workforce and links to a multinational group have higher probabilities of relocating. In a more recent study, Sleuwaegen and Pennings (2006) used a similar dataset for Belgium with the aim of testing the following two hypotheses: first, if smaller firms relocate to a nearby location whereas larger firms move to a more remote location and, second, whether public aid distorts relocation decisions. They found that wages and market potential in a host region are important determinants for the location choice. Firm characteristics are also relevant as large firms have a higher propensity to relocate to remote countries, while public aid seems to affect only the decisions of firms moving to an adjacent region.

Using an approach similar to Pennings and Sleuwaegen (2000), Van Dijk and Pellenbarg (2000) analysed the Dutch case and their main finding is that only factors internal to a firm and (surprisingly) external factors seem to have no effect on a firm's propensity to relocate.

Holl (2004) examined location determinants of domestic relocation in Portugal, comparing the situation in 1997 with the one observed in 1986. Relocation appears to be positively associated with domestic market accessibility, 
availability of producer services, and a large industrial base. Relocations are also more strongly attracted by the provision of inter-regional motorways.

Perhaps the most extensive study of this issue is the one by Brouwer et al. (2004). Using a multi-country dataset, they found a different result to Van Dijk and Pellenbarg (2000): the economic environment of firms does affect their mobility decisions. In particular, they found that change in a firm's demand is one of the key determinants of relocation.

Subcontracting and outsourcing have also been analysed from empirical perspectives, although the number of studies using microdata is substantially lower. For example, O'Farrell et al. (1993) analyse the demand by manufacturers in Scotland and South East England for key strategic business services. Their evidence suggests that variations in demand-and not restructuring strategies-are the primary cause of outsourcing. However, Doi (1999) obtained opposite results. In particular, he found that subcontracting relationships have an exit promoting effect on Japanese firms in the period 1981-1989. A possible explanation could be that exit costs are lower for firms with subcontractors than for firms with in-house production, since sunk costs are higher for plant closure than for rescinding subcontracting agreements. The Japanese case was also analysed by Kimura (2002). In particular, he analysed subcontracting determinants of the Japanese machinery industry where this kind of arrangement is particularly relevant. He found that firm size does not seem to affect the use of subcontractors and that foreign-owned firms use subcontractors in a higher proportion.

In summary, the theoretical and the empirical literature allow us to identify three main categories of factors influencing firm decisions about outsourcing and relocation that should be considered: internal factors (i.e. size, age or sector), external factors (i.e. market size) and location factors (i.e. region).

\section{Empirical evidence}

\subsection{The dataset and the empirical model}

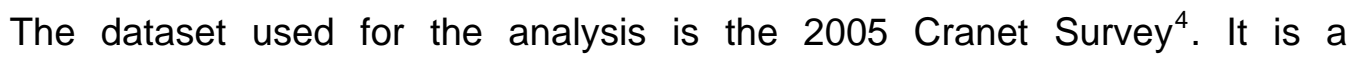
representative survey of Human Resource Management policies and practices, based on standardised questionnaires and regularly carried out by several universities and business schools since 1990. It includes information about nearly 8,000 private and public firms located in 32 countries. The answers are related to the period 2003-2005.

An important difference related to the study by Brouwer et al. (2004), which uses a similar dataset, is that we do not limit our analysis to firms with more

\footnotetext{
${ }^{4}$ For more details, see http://www.cranet.org.
} 
than 200 employees. However, we do not consider the answers of multi-plant firms which have not been disaggregated at the plant level. The reason for excluding these firms is that we would not be able to identify properly the firm characteristics that led to relocation or subcontracting. In particular, it would be impossible to distinguish the effect of size on relocation decisions from the influence of a higher number of plants. While large single-site firms are less willing to move, large multi-plant firms have a higher propensity to move because they have more plants that can be relocated (Pennings and Sleuwaegen, 2000). After excluding these observations, our initial effective sample includes the answers from 7,809 firms from more than 30 countries. Of these firms, 4,119 were located in the European Union (EU).

As stated in previous sections of the paper, we will focus our analysis on those firms in which there has been a reduction in employment during the reference period. Between 2002 and 2005, employment decreased in 2,413 out of the 7,809 firms considered ( $31 \%$ of the total sample). In the EU countries ${ }^{5}$, there were job losses in 1,388 firms (34\% of total firms). Thus, in one out of three firms, employment decreased.

This decrease in employment was related to the recent downturn in economic activity both at the global level and at the EU level. In response to lower demand for their products and reduced margins, firms could use various strategies: they could, for example, relocate their production to a more favourable location (i.e. with lower wages) or externalise part of their production by outsourcing.

Both outsourcing and relocation were used with this aim by firms in the sample. When considering all countries, $12.0 \%$ of firms used outsourcing as a way of reducing employment and $9.3 \%$ of firms underwent relocation. For EU firms, these values were $13.2 \%$ and $11.8 \%$. It is worth mentioning that, using data for the period 1995-1997, Brouwer et al. (2004) found that the percentage of firms involved in relocation decisions was $8.0 \%$. That percentage is lower than the one found here, although the two values are not strictly comparable, because Brouwer et al. (2004) analysed firms with more than 200 employees and did not limit their study to those where employment had decreased.

If we concentrate on the firms in which employment decreased during the period under consideration for all the countries, $11.0 \%$ of these firms were involved in a relocation decision and $34.6 \%$ used outsourcing to reduce their workforce. The values for firms located in the EU are higher in both cases: $13.9 \%$ of firms were involved in relocation decisions and $35.5 \%$ used outsourcing ${ }^{6}$.

\footnotetext{
${ }^{5}$ No information is available for Ireland, Luxembourg and Portugal.

6 Although our objective is to analyse the behaviour of firms in which employment has decreased, we have also replicated the empirical analysis with the full sample. The obtained results are in line with the ones shown here and are available from the authors on request.
} 
In order to identify the determinants of both decisions in those firms where employment decreased, two logit models are specified, with the additional aims of checking whether there are any differences between the two decisions and whether firm behaviour is dependent on location (i.e. in the EU).

Taking the literature review into account, three main categories of factors influencing firm decisions regarding outsourcing and relocation should be considered: internal factors (i.e. size, age or sector), external factors (i.e. market size) and location factors (i.e. region). All this information was available in the Cranet database.

With the sole exception of the decrease in employment, which is expressed as a percentage of total employees in a firm, the explanatory variables are all dummy variables. A first group of dummy variables is related to firm size measured by number of employees. A second group is related to firm age. Firc sector and the main marker for products and services are also controlled. The next group of dummy variables is related to changes in firm organisation during the last three years: in particular, whether a firm was involved in any acquisition, takeover, merger or demerger. The institutional framework in which a firm operates is controlled for, using country fixed-effects, and the headquarters location of firms belonging to multinational groups is also controlled. The last group of variables is related to the relative performance of a firm with respect to several aspects that could affect outsourcing and relocation decisions. The results of estimating these models are shown in the next sub-section.

\subsection{Empirical results}

Table 2 sets out the estimates based on the logit model for outsourcing, while table 3 presents the model's estimates for relocation decisions.

\section{TABLES 2 AND 3}

Regarding firm size, the results show that smaller firms have a lower probability of outsourcing in order to externalise part of their production than medium or large firms do. This result is probably related to the fact that smaller firms may encounter more difficulties adjusting their production processes quickly to higher capital-to-labour ratios. As regards relocation decisions, we find that firm size significantly affects such decisions only for smaller firms in the EU sample. In particular, firms located in the EU with less than 30 employees have a higher probability of undertaking relocation in the context of job destruction than bigger firms do. This result is common in the literature. For example, Brouwer et al. (2004) found that firms with more than 1,500 employees are less willing to move than smaller firms. 
Firm age does not affect its outsourcing decisions, but it does affect relocation decisions for firms located in the EU. Middle-aged firms have a lower propensity to relocate than younger or older ones. This result is consistent with institutional theories highlighting the fact that older firms usually take part in networks that are difficult to break, but it was expected that younger firms would have a higher propensity to relocate. Nevertheless, this result is not uncommon in the literature because these kinds of studies encounter a complicating factor in that firm age and size are highly correlated, so that the separate effects of each are difficult to disentangle (see Pellenbarg et al., 2000).

From a sectoral perspective, there are no relevant significant differences in outsourcing or relocation decisions. This is a standard result in the literature except for commercial services, which have been found, in general, to be more mobile than other sectors (Brouwer et al., 2004). However, our data does not support that general evidence.

The main market of a firm does not affect outsourcing decisions in the sample for all countries, but it does in the EU sample. As expected, firms serving the European market in particular have a higher probability of outsourcing, which is a clear signal that some advances have been made during the last few years in terms of market integration. Regarding relocation, firms serving domestic markets have a higher probability of outsourcing and relocation in both samples. This is also the expected result as domestic markets are the ones undergoing greater change due to integration processes and the recent economic recession.

As regards changes in firm organisation, involvement in merger and demerger activity in the sample of all countries, as well as solely demerger involvement in the European sample, has significant effects on outsourcing decisions. Regarding relocation, all changes in firm organisation under consideration have significant effects in the sample for all countries, while in the EU-15 sample, only acquisition and demerger activity seem to have effects on relocation. This result is similar to the one found by Brouwer et al. (2004).

In several countries, the probability of outsourcing is higher than in the United Kingdom (the reference category). In particular, this probability is higher for most EU-15 countries, with few exceptions: Belgium, France, Greece and Italy. This is also true for the USA and some of the new EU member states: the Czech Republic, Estonia and Slovenia. Country differences are less marked when analysing relocation decisions. Our dataset does not allow the reasons behind these cross-country differences to be explored, but it poses an interesting topic for future research, from the perspective of policy analysis.

Firms that belong to a multinational group and have headquarters located in the EU or North America also have a higher probability of outsourcing. With 
respect to relocation, differences arise when comparing the sample for all countries with the sample for the EU-15 countries. In the sample for all countries, firms belonging to a group with headquarters in Europe (inside or outside the European Union) or in North America have a higher probability of relocation. In the EU-15 sample, only firms with headquarters in North America have higher probabilities of relocation.

The last set of dummy variables is related to the relative performance of a firm within its own sector with respect to several aspects: quality, productivity, profitability, time to market, and innovation. Firms that are below their sector average in quality and innovation have a higher propensity to outsource, while the other factors do not have any significant effects. However, when looking at relocation decisions, profitability and time to market are the only relevant factors: low profitability firms have a higher probability of relocating, while firms with faster than average time to market have a lower probability of relocating.

Lastly, a greater decrease in a firm's employment implies a higher probability of outsourcing, but not a higher probability of relocation.

\section{Final remarks}

Using microdata on firms for the period 2003-2005, we analyse the determinants of conventional outsourcing and firm relocation in the context of falling demand, putting special attention on EU countries. One relevant result is that there are only minor differences between EU countries and the other countries included in the Cranet database. Moreover, the results obtained allow us to conclude that there are determinants common to both decisions, such as the market served by a firm, recent changes in firm organisation, the institutional framework, belonging to a multinational group, and poor relative performance within the sector. However, while firm size has some effect on outsourcing, it does not have any effect on relocation decisions. Firm age does not affect outsourcing decisions, but it does affect relocation decisions. Firms that are below the sector average in quality or innovation have a higher propensity to outsource, while lower profitability or longer time to market each imply a higher probability of relocation. Further, a decline in employment is usually followed by outsourcing part of production, whereas the same cannot be said for relocation decisions. Lastly, there are no significant differences across sectors with respect to either outsourcing or relocation. From our point of view, these results are particularly interesting from the perspective of policy makers, as they may facilitate the development of appropriate strategies to minimise the potential risks of job losses in a given area.

\section{REFERENCES}


Amiti, M. and Wei, S-J. (2005): "Fear of services outsourcing. Is it justified?" Economic Policy, April, pp. 307-347.

Barthélemy, J. and Geyer, D. (2005): "An empirical investigation of IT outsourcing versus quasi-outsourcing in France and Germany", Information and Management, vol. 42, pp. 533-542.

Brouwer, A. E., Mariotti, I. and van Ommeren, J. (2004): "The firm relocation decision: An empirical investigation", Annals of Regional Science, 38, 335347.

Boulhol, H. and Fontagné, L. (2006): Deindustrialisation and the fear of relocations in the industry, CEPII working paper 2006-07. Available at www.cepii.fr.

Doi, N. (1999): "The determinants of firm exit in Japanese manufacturing industries", Small Business Economics, vol. 13, pp. 331-337.

Holl, A. (2004): "Start-ups and relocations: manufacturing plant location in Portugal", Papers in Regional Science, vol. 83, pp. 649-68.

Kimura, F. (2002): "Subcontracting and the Performance of Small and Medium Firms in Japan”, Small Business Economics, vol. 18, pp. 163-175.

O'Farrell, P. N., Hichens, D. M. and Moffat, L. A. R. (1993): "Manufacturing Demand for Business Services in a Core and Peripherical Region: Does Flexible Production Imply Vertical Disintegration of Business Services?" Regional Studies, vol. 27, pp. 519-533.

Pellenbarg, P., van Wissen, L., van Dijk, J. (2002): Firm relocation: State of the art and research prospects, University of Groningen SOM Research Report $02 \mathrm{D} 31$.

Pennings, E. and Sleuwaegen, L. (2000): "International relocation: firm and industry determinants", Economics Letters, vol. 67, pp. 179-186.

Sleuwaegen, L. and Pennings, E. (2006): "International relocation of production: Where do firms go?", Scottish Journal of Political Economy, vol. 53, pp. 430-446.

Taymaz, E. and Kiliçaslan, Y. (2005): "Determinants of subcontracting and regional development: An empirical study on Turkish textile and engineering industries", Regional Studies, vol. 39, pp. 633-645. 
Van Dijk, J. and Pellenbarg, P. H. (2000), "Firm relocation decisions in the Netherlands: An ordered logit approach?", Papers in Regional Science, vol. 79, pp. 191-219.

\section{TABLES}

Table 1. Theories and potential determinants of Relocation and subcontracting decisions

\begin{tabular}{|c|c|c|}
\hline & Theory & Potential determinants \\
\hline \multirow[t]{3}{*}{ Relocation } & Locational & Location factors: market size, etc \\
\hline & Behavioural & Internal factors: firm size, firm age, etc. \\
\hline & Institutional & External factors: firm growth or decline, $\ldots$ \\
\hline \multirow[t]{4}{*}{ Subcontracting } & Transaction costs & Internal factors: technology or labour-intensive \\
\hline & Game theory & Internal factors: firm size, firm age, etc. \\
\hline & Informational economics & Internal factors: monitoring costs, etc. \\
\hline & Network approach & External and location factors: industrial clusters, etc. \\
\hline
\end{tabular}


Table 2. Results of the maximum likelihood estimation of a logit model for outsourcing decisions (1/3)

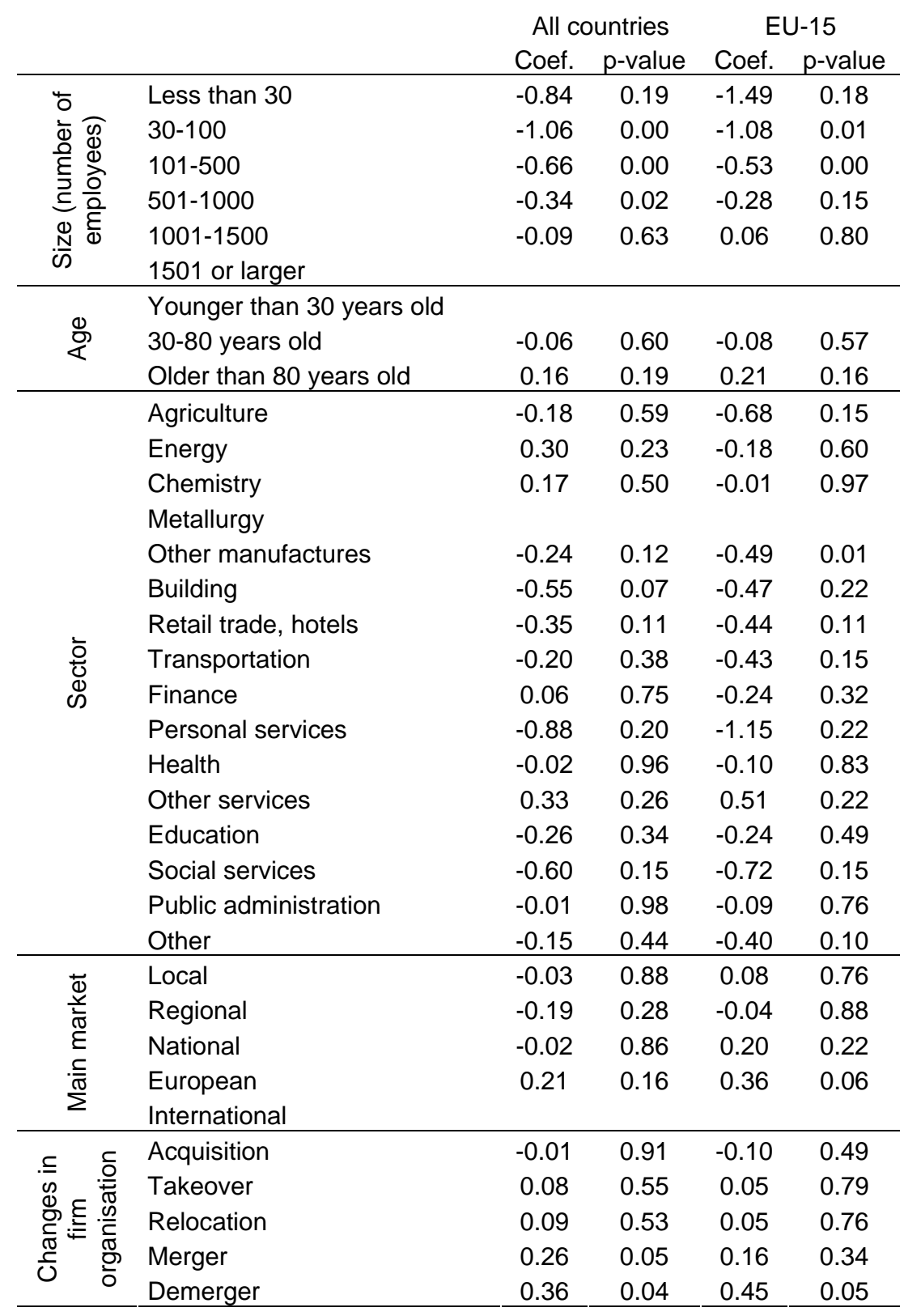


Table 2. Results of the maximum likelihood estimation of a logit model for outsourcing decisions (2/3)

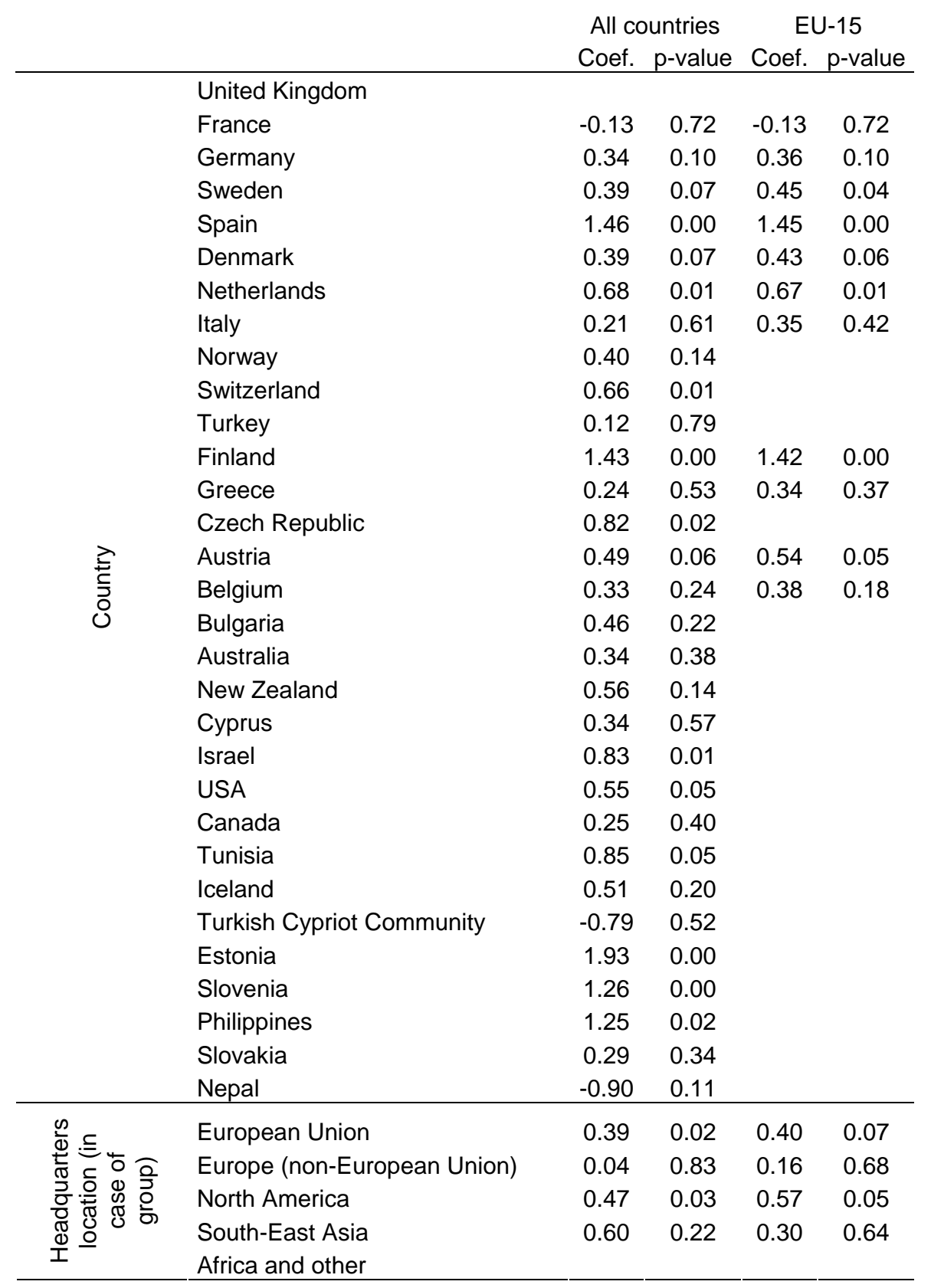


Table 2. Results of the maximum likelihood estimation of a logit model for outsourcing decisions (3/3)

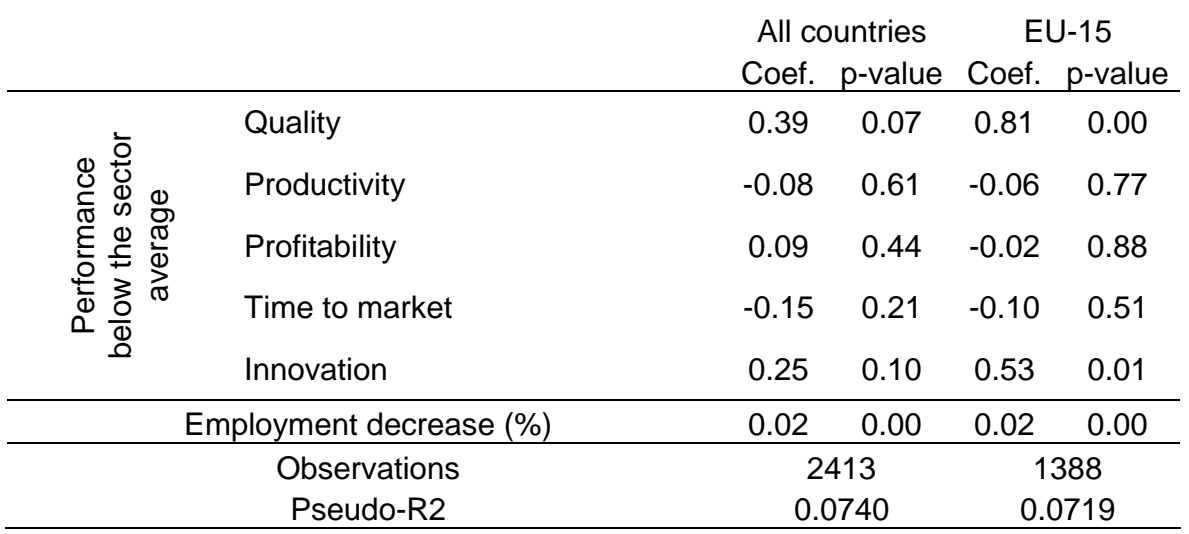


Table 3. Results of the maximum likelihood estimation of a logit model for relocation decisions (1/3)

\begin{tabular}{|c|c|c|c|c|c|}
\hline & & \multicolumn{2}{|c|}{ All countries } & \multicolumn{2}{|c|}{ EU-15 } \\
\hline & & Coef. & $p$-value & Coef. & p-value \\
\hline \multirow{6}{*}{ 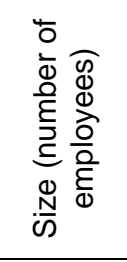 } & Less than 30 & 0.79 & 0.25 & 1.78 & 0.03 \\
\hline & $30-100$ & -0.04 & 0.89 & -0.10 & 0.84 \\
\hline & $101-500$ & -0.13 & 0.49 & -0.03 & 0.89 \\
\hline & $501-1000$ & -0.27 & 0.25 & 0.08 & 0.75 \\
\hline & $1001-1500$ & -0.13 & 0.66 & -0.02 & 0.96 \\
\hline & 1501 or larger & & & & \\
\hline \multirow{3}{*}{$\underset{8}{\mathscr{Q}}$} & Younger than 30 years old & & & & \\
\hline & $30-80$ years old & -0.21 & 0.23 & -0.35 & 0.09 \\
\hline & Older than 80 years old & -0.10 & 0.60 & -0.07 & 0.72 \\
\hline \multirow{16}{*}{$\begin{array}{l}\overline{0} \\
\text { d } \\
心\end{array}$} & Agriculture & 0.70 & 0.12 & 0.78 & 0.13 \\
\hline & Energy & 0.26 & 0.47 & 0.74 & 0.09 \\
\hline & Chemistry & -0.36 & 0.39 & -1.52 & 0.02 \\
\hline & Metallurgy & & & & \\
\hline & Other manufactures & -0.12 & 0.63 & -0.20 & 0.49 \\
\hline & Building & -0.50 & 0.28 & -0.11 & 0.82 \\
\hline & Retail trade, hotels & -0.34 & 0.31 & -0.20 & 0.60 \\
\hline & Transportation & -0.22 & 0.53 & -0.48 & 0.23 \\
\hline & Finance & 0.20 & 0.47 & 0.13 & 0.68 \\
\hline & Personal services & & & & \\
\hline & Health & -0.07 & 0.89 & -0.10 & 0.88 \\
\hline & Other services & 0.27 & 0.52 & -0.03 & 0.96 \\
\hline & Education & -0.41 & 0.37 & -0.18 & 0.74 \\
\hline & Social services & -0.66 & 0.41 & -0.39 & 0.64 \\
\hline & Public administration & -0.09 & 0.82 & 0.24 & 0.56 \\
\hline & Other & 0.07 & 0.80 & 0.09 & 0.77 \\
\hline \multirow{5}{*}{ 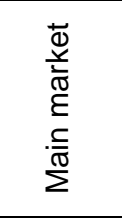 } & Local & -0.14 & 0.70 & -0.55 & 0.23 \\
\hline & Regional & 0.29 & 0.27 & 0.12 & 0.71 \\
\hline & National & 0.36 & 0.04 & 0.31 & 0.10 \\
\hline & European & 0.12 & 0.59 & 0.18 & 0.47 \\
\hline & International & & & & \\
\hline \multirow{5}{*}{ 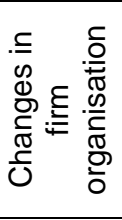 } & Acquisition & 1.00 & 0.00 & 0.99 & 0.00 \\
\hline & Takeover & 0.32 & 0.09 & 0.27 & 0.23 \\
\hline & Relocation & & & & \\
\hline & Merger & 0.54 & 0.00 & 0.26 & 0.20 \\
\hline & Demerger & 0.62 & 0.01 & 0.54 & 0.05 \\
\hline
\end{tabular}


Table 3. Results of the maximum likelihood estimation of a logit model for relocation decisions (2/3)

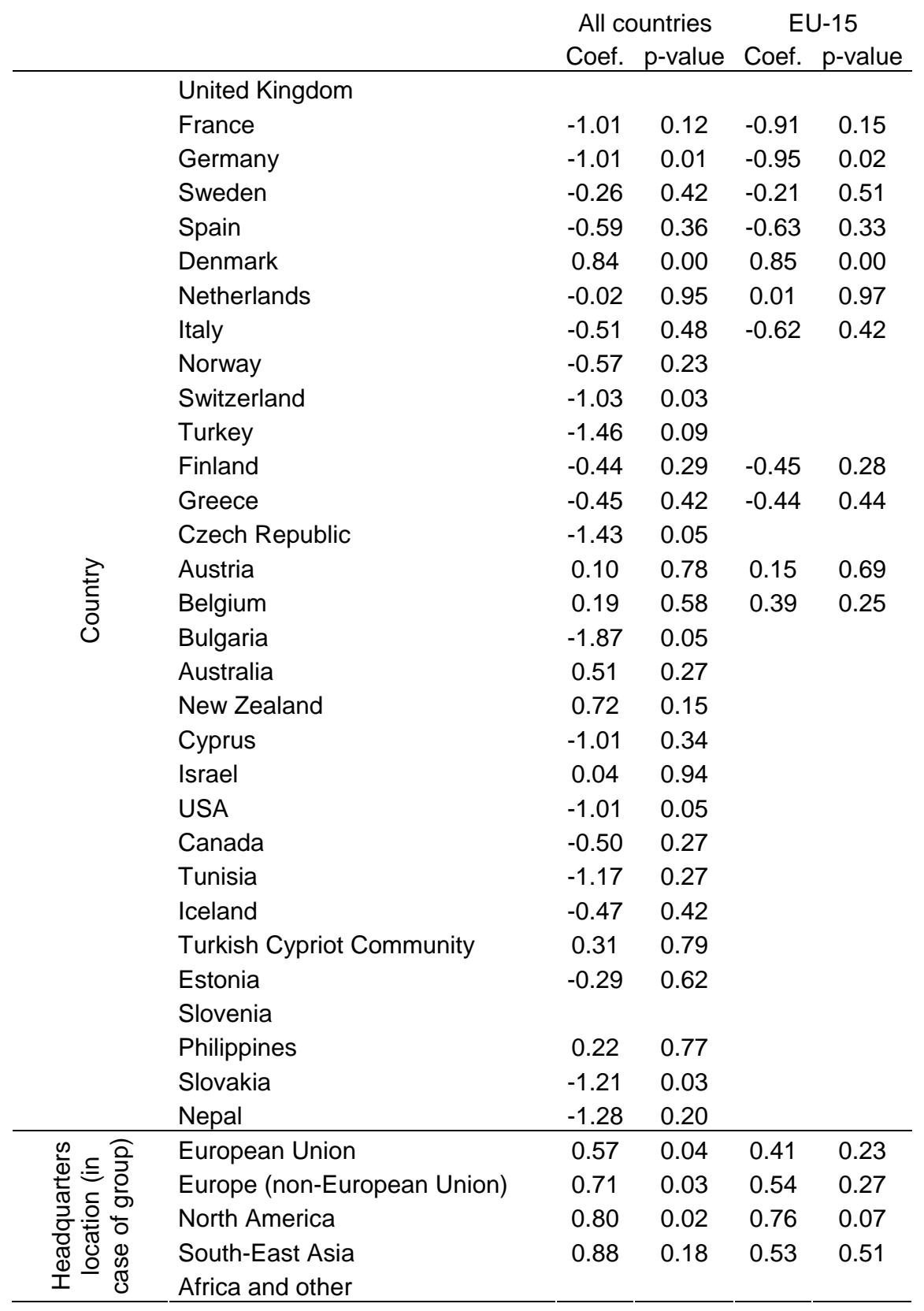


Table 3. Results of the maximum likelihood estimation of a logit model for relocation decisions (3/3)

\begin{tabular}{|c|c|c|c|c|c|}
\hline \multirow{7}{*}{ 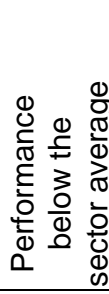 } & & \multicolumn{2}{|c|}{ All countries } & \multicolumn{2}{|c|}{ EU-15 } \\
\hline & & Coef. & $p$-value & Coef. & $\mathrm{p}$-value \\
\hline & Quality & 0.30 & 0.36 & 0.56 & 0.16 \\
\hline & Productivity & -0.08 & 0.72 & -0.09 & 0.73 \\
\hline & Profitability & 0.41 & 0.02 & 0.44 & 0.04 \\
\hline & Time to market & -0.32 & 0.09 & -0.36 & 0.09 \\
\hline & Innovation & 0.12 & 0.59 & 0.09 & 0.72 \\
\hline \multicolumn{2}{|c|}{ Employment decrease (\%) } & 0.01 & 0.27 & 0.01 & 0.18 \\
\hline & Observations & \multicolumn{2}{|c|}{2350} & \multicolumn{2}{|c|}{1383} \\
\hline & Pseudo-R2 & \multicolumn{2}{|c|}{0.1347} & \multicolumn{2}{|c|}{0.1201} \\
\hline
\end{tabular}

